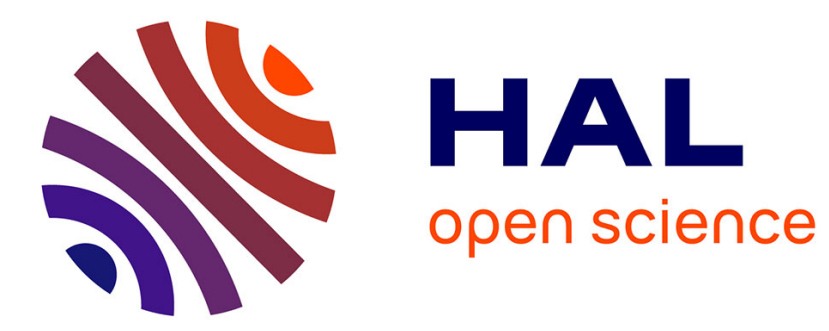

\title{
Isothermal relaxation of discommensurations in $\mathrm{K} 2 \mathrm{ZnCl} 4$
}

\author{
G. Niquet, Mario Maglione, A. Gueldry, V. Sigoillot
}

\section{To cite this version:}

G. Niquet, Mario Maglione, A. Gueldry, V. Sigoillot. Isothermal relaxation of discommensurations in K2ZnCl4. Journal de Physique I, 1994, 4 (8), pp.1173-1180. 10.1051/jp1:1994247 • jpa-00246977

\section{HAL Id: jpa-00246977 https://hal.science/jpa-00246977}

Submitted on 1 Jan 1994

HAL is a multi-disciplinary open access archive for the deposit and dissemination of scientific research documents, whether they are published or not. The documents may come from teaching and research institutions in France or abroad, or from public or private research centers.
L'archive ouverte pluridisciplinaire HAL, est destinée au dépôt et à la diffusion de documents scientifiques de niveau recherche, publiés ou non, émanant des établissements d'enseignement et de recherche français ou étrangers, des laboratoires publics ou privés. 
Classification

Phystcs Abstracts

$64.70 \mathrm{R}-77.20$

\title{
Isothermal relaxation of discommensurations in $\mathrm{K}_{2} \mathrm{ZnCl}_{4}$
}

\author{
G. Niquet, M. Maglione, A. Gueldry and V. Sigolllot \\ Laboratoire de Physique (*), Universıté de Bourgogne, BP 138, 21004 Dijon Cedex, France
}

(Recelved 9 July 1993, revised 12 Aprll 1994, accepted 5 May 1994)

\begin{abstract}
Résumé. - Au voisinage de la température, $T_{\mathrm{c}}$, de transitıon incommensurable-ferroélectrique, la susceptıbilité de $\mathrm{K}_{2} \mathrm{ZnCl}_{4}$ présente une contribution anormale. Des mesures diélectriques quasistatiques et la courbe d'hystérésis montrent que cette partie anormale provient de la dynamique partıculière des discommensurations. En utılisant des mesures diélectriques isothermes nous avons trouvé, en accord avec les résultats obtenus dans $\mathrm{Rb}_{2} \mathrm{ZnCl}_{4}$, que le temps caractéristique de relaxation est de 1 ordre de $10^{4} \mathrm{~s}$ dans les 2 phases. Dans une petıte gamme de température au voisinage de $T_{\mathrm{c}}$ nous avons observé une relaxation non monotone liée au blocage des discommensurations par des défauts. Pour la première fois nous montrons que le temps caractérıstıque de cette relaxatıon particulıère augmente à la même température au refroıdissement ou au chauffage.
\end{abstract}

\begin{abstract}
At the incommensurate-ferroelectric transition temperature $T_{\mathrm{c}}$ of $\mathrm{K}_{2} \mathrm{ZnCl}_{4}$, the dielectric susceptıbility contans an anomalous contribution both above and below $T_{c}$. Previous quasi-static dielectric measurements and hysteresis loops demonstrated that this anomalous part arises from the peculıar dynamics of discommensurations. We have used isothermal dielectric measurements to get some insight into the long time dynamics of these discommensurations. We have found that the characteristic relaxation times $\tau$ are of the order $10^{4} \mathrm{~s}$ in the incommensurate and in the ferroelectric phase. Even more unusual is a non-monotonous relaxation which is observed in a restricted temperature range above and below $T_{\mathrm{c}}$. In agreement with previous results in $\mathrm{Rb}_{2} \mathrm{ZnCl}_{4}$, this is ascribed to the pinning of discommensurations by defects. We show, for the first time, that the crossover tıme of this peculıar relaxatıon increases drastically at the same temperature under etther heatıng or coolıng conditions.
\end{abstract}

\section{Introduction.}

Among the family of $\mathrm{A}_{2} \mathrm{BX}_{4}$ compounds, $\mathrm{K}_{2} \mathrm{ZnCl}_{4}$ is the one which displays the most interesting thermodynamical properties. The temperature interval where these effects are seen lies in the vicinity of the lock-in transition temperature $T_{c}$ which separates the high temperature incommensurate phase from the low temperature ferroelectric phase.

From the beginning, it was shown that the dielectric anomaly at $T_{\mathrm{c}}$ was sensitive to the temperature variation rate [1]. Startıng from an as-grown sample Unruh could monitor the

(*) Associated to the CNRS (URA 1796). 
magnitude and the position of the dielectric anomaly by appropriate temperature cycling and annealing [2]. The minımum thermal hysteresis of $4 \mathrm{~K}$ was achieved after a cooling run at $0.007 \mathrm{~K} / \mathrm{min}$ [2]. At $T_{\mathrm{c}}-100 \mathrm{~K}$, room temperature hysteresis cycles are evolving on a tıme scale of weeks.

It seems that the thermodynamical properties of $\mathrm{K}_{2} \mathrm{ZnCl}_{4}$ above and below $T_{\mathrm{c}}$ result from a nucleation-growth-rearrangement process of the discommensurations [2].

A clear connection of this slow dynamics with the discommensuration motion was inferred from direct TEM observations [3]. Based on the general model of the dielectric susceptibility in $\mathrm{A}_{2} \mathrm{BX}_{4}$ compounds [4] a topology of the discommensurations was proposed.

A macroscopic description of this process was given by Hamano et al. [5] using radiofrequency dielectric dispersion data. A Debye type relaxation was observed in the ferroelectric (C) and in the incommensurate (IC) phase. This relaxation was ascribed to the domain wall motion in the $C$ phase and to the discommensuration dynamics in the IC phase. In the vicinity of $T_{\mathrm{c}}$ a crossover between these two relaxations was reported, giving a direct insight into the gradual transformation of ferroelectric domain wall into incommensurate discommensuration. The non-monotonous time variation of the relaxation step $\varepsilon_{1}(1 \mathrm{MHz})-\varepsilon_{1}(100 \mathrm{MHz})$ was a signature of this process.

Low frequency dielectric experiments and X-ray diffraction confirmed this behaviour $[6,7]$. A clear connection was found between the time evolution of the satellite line intensity and the dielectric maximum.

However, these isothermal experiments were performed only at a few temperatures. It is the aim of the present work to extend the isothermal dielectric experiments in order to get some insight into the gradual transformation of the monotonous relaxation away from $T_{\mathrm{c}}$ to the nonmonotonous relaxation in the vicinity of $T_{c}$.

\section{Sample preparation and experıments.}

The $\mathrm{K}_{2} \mathrm{ZnCl}_{4}$ crystals used in this study were grown in aqueous solutions of $\mathrm{KCl}$ and $\mathrm{ZnCl}$ following the standard conditions. The impurity content of these crystals was probed by several chemical analysis. We found 130 p.p.m. at. of sodium and 500 p.p.m. at. of calcium as the major impurities, other elements being below the analysis sensıbility (about 1 p.p.m. at.).

Three samples were cut from the same crystal. After polishing, gold electrodes were always evaporated on the faces perpendicular to the $b$ axis which is the ferroelectric axis. To compare our samples with the standard low-defects $\mathrm{K}_{2} \mathrm{ZnCl}_{4}$, we performed the same temperature run as Unruh [2] : the sample was first annealed at $450 \mathrm{~K}$ for $20 \mathrm{~h}$, then cooled down to $350 \mathrm{~K}$ at a rate of $0.006 \mathrm{~K} / \mathrm{min}$ and then heated again at the same rate. Under these conditions, the dielectric susceptıbility that we have recorded follows approx imately the results of Mashiyama et al. [6], showing that the amount of defects in our samples is comparable to that used in previous studies.

It was then possible to apply our experimental procedure. This procedure was two fold : under heating and under coolıng conditions. Under heatıng conditions, the sample was heated from room temperature up to the operating temperature $T_{\mathrm{s}}$ at a rate of $0.5 \mathrm{~K} / \mathrm{min}$. While keeping $T_{s}$ stable with a precision better than $0.01 \mathrm{~K}$, we recorded the time evolution of $\varepsilon_{1}$, the real part of the dielectric susceptibility.

Under cooling conditıons, starting from room temperature, the sample was heated up to $450 \mathrm{~K}$ at a rate of $0.5 \mathrm{~K} / \mathrm{min}$ and then immediately cooled to the operating temperature $T$, with the same rate. The dielectric susceptibility $\varepsilon_{1}$ was recorded at $T$, under the same conditions as for heating cycles. We have used a rather high thermal variation rate in order to keep the samples far from equilibrium and to test both the fast and slow isothermal relaxatıons. 
The test signal frequency of the HP4 192 bridge was $100 \mathrm{kHz}$, i.e. much below the frequency range where dispersive effects occur [5]. The signal amplitude was $1 \mathrm{~V}$ peak-peak and the overall connection capacitance was lower than $0.02 \mathrm{pF}$. To avoid possible irreversible ageing of our samples we ensured that the absolute value of $\varepsilon_{1}$ was reproducible at any temperature within $0.1 \%$. The operatıng temperatures $T$, were set randomly in order to avoid any systematic and unwanted effects of the sample history.

\section{Results.}

We first describe our dielectric data under temperature cycling. At all temperatures, the absolute value of $\varepsilon_{1}$ is nearly the same as that reported by Mashiyama et al. [6]. When the temperature variation rate is high $(0.5 \mathrm{~K} / \mathrm{min}$ ), we find a hysteresis of $24 \mathrm{~K}$ (curves $\mathrm{A}$ in Figs. $1 \mathrm{a}$ and $1 \mathrm{~b}$ ). Using a slow cycle, this thermal hysteresis was reduced to $5 \mathrm{~K}$ with a temperature variation rate of $0.006 \mathrm{~K} / \mathrm{min}$ (curves $B$ in figs, $1 \mathrm{a}$ and $1 \mathrm{~b}$ ).

Applying the experimental procedure described above, the starting points of all the isothermal relaxations lie on curves $\mathrm{A}$. In fact, the temperature variation rate of all the temperature cycles preceding the isothermal experiments was $0.5 \mathrm{~K} / \mathrm{min}$ which is the rate of curves $A$. At the end of the isothermal experiments, the samples were close to the dielectric curves B. We thus tested the relaxation from curves A to curves B, i.e. from an out-ofequilibrium state to a near-equilibrium state. This leads to the specific features of each temperature range that we have pointed out in figure 1.

Far from the critical regime, in region $\mathrm{I}$, we have detected no isothermal relaxation. In region II, where the fast and slow cooling (heating) curves start diverging, the isothermal relaxation is an increasing function of time (curves II in Figs. $2 a$ and $2 b$ ). We have fitted this data using the stretched exponential law proposed by Mashiyama [7]

$$
\varepsilon_{1}(t) \approx \varepsilon_{\infty}-\Delta \varepsilon \exp \left(-\sqrt{\frac{t}{\tau}}\right)
$$

where $\varepsilon_{\infty}$ is the near equilibrium susceptibility and $\tau$ is the relaxation time.

The same law holds for the decrease which was observed in region IV but with a plus sign preceding the exponentral.

The most interesting relaxation that we actually report lies in region III. In fact, in this temperature interval, the isothermal relaxation is a non-monotonous function of time: $\varepsilon_{1}$ first increases, reaches a maxımum at a time $t_{0}$ and finally slowly decreases for $t>t_{0}$ (curves III in figs. $2 \mathrm{a}$ and $2 \mathrm{~b}$ ). This relaxation is qualitatively sketched in figure 1 for a temperature $T_{\mathrm{s}}$ within region III. Starting from curve $A$, the dielectric susceptibility first increases, reaches a virtual maximum and then decreases toward the near-equilibrium susceptibility at $T_{\varsigma}$. As displayed in figure 1, the border of regions III are not well defined. This is because the regions were determined experimentally and the shortest $t_{0}$ that we could detect is of the order of $10 \mathrm{~s}$. This limit was set after several tests in order to ensure thermal equilibrium within the sample. A non-monotonous variation of $\varepsilon_{1}$ may be observed outside of regions III for shorter time scales. We recall that the operatıng temperatures were set randomly. However, the non-monotonous relaxation in region III was systematically reproducible.

In particular, the relaxations are qualitatively similar under either cooling or heating conditions. The fitting of such data is not easy. In $\mathrm{Rb}_{2} \mathrm{ZnCl}_{4}$, the monotonous relaxation was fitted using a superposition of 2 stretched exponentials as given in equatıon (1) [11]. These two relaxations were ascribed to the dynamics of discommensurations and ferroelectric domain walls which both decrease the dielectric susceptibility. Our non-monotonous data cannot be modelled in the same way. 

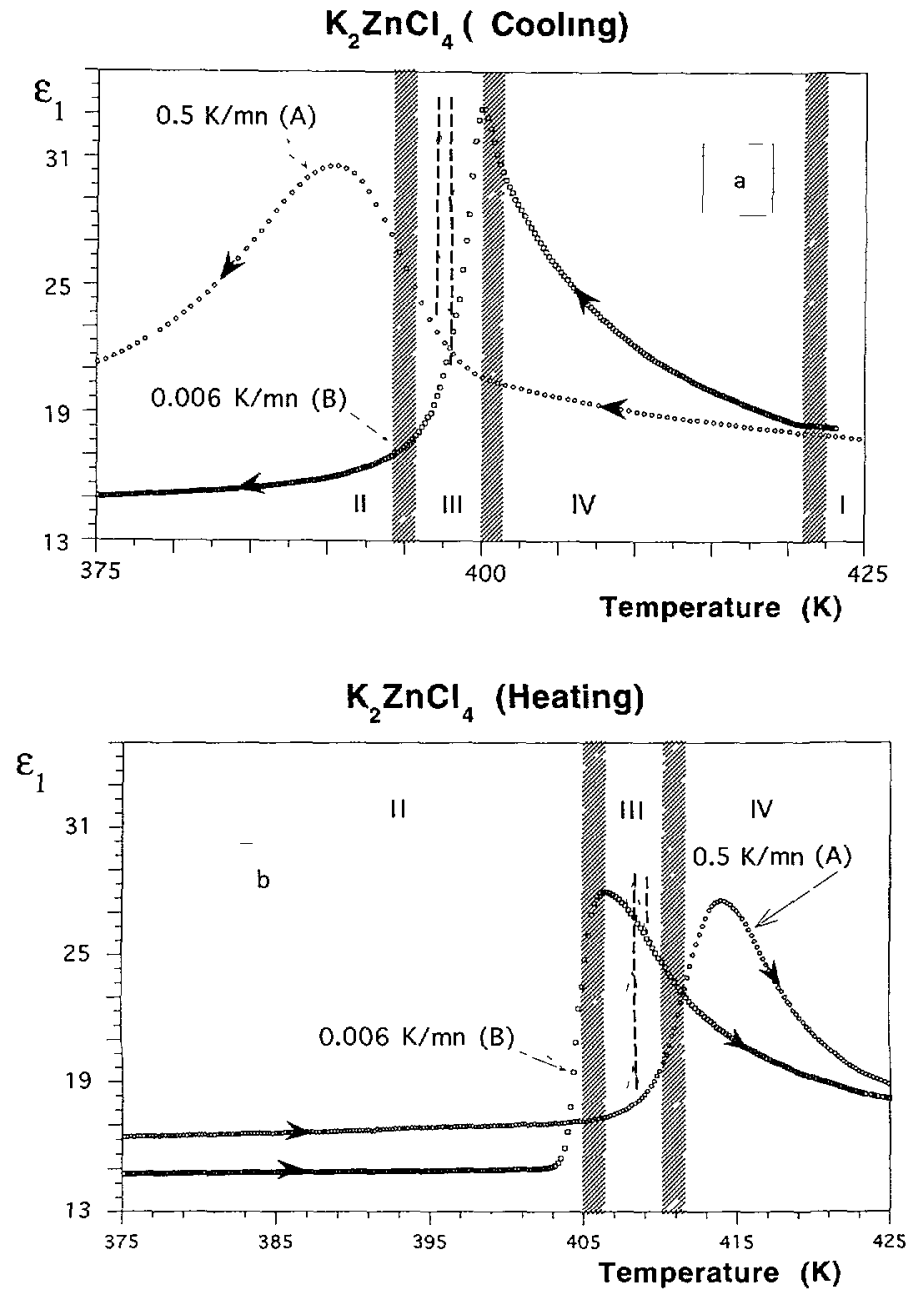

Fig. 1. - Dielectric susceptibility versus temperature for $\mathrm{K}_{2} \mathrm{ZnCl}_{4}$ under cooling (a) and under heatıng (b). Curves A were recorded under the fast temperature variation rate of $0.5 \mathrm{~K} / \mathrm{min}$ and curves $\mathrm{B}$ under the slow rate of $0.006 \mathrm{~K} / \mathrm{mm}$. The border lines between the isothermal regimes I-II-III-IV have been determined experimentally. The isothermal behaviour is schematically sketched by the arrows in temperature region III. Hatched areas point out the imprecision of region limits.

This is why the only parameter that we have recorded versus temperature is the crossover tıme $t_{0}$ where the susceptibility reaches its maxımum. In figure 3 , we have plotted this crossover time $t_{0}$ as a function of temperature. It clearly increases at $T_{\mathrm{c}}$ under both heatıng or cooling conditions.

Outside this interval III, the susceptibility relaxes directly from the non-equilibrium to the near-equilibrium susceptibilities (regions IV). In these temperature ranges we fixed $t_{0}=0$.

To summarize our experimental results qualitatively, we point out that the succession of Isothermal relaxations I-II-III-IV is the same under elther cooling or heatıng conditions. This was rather unexpected since the isothermal susceptibility relaxation is generally thought to arıse from discommensurations kinetıcs. This kinetics has not to be the same when starting from the ferroelectric phase or from the incommensurate phase. We can ascribe the reversible 

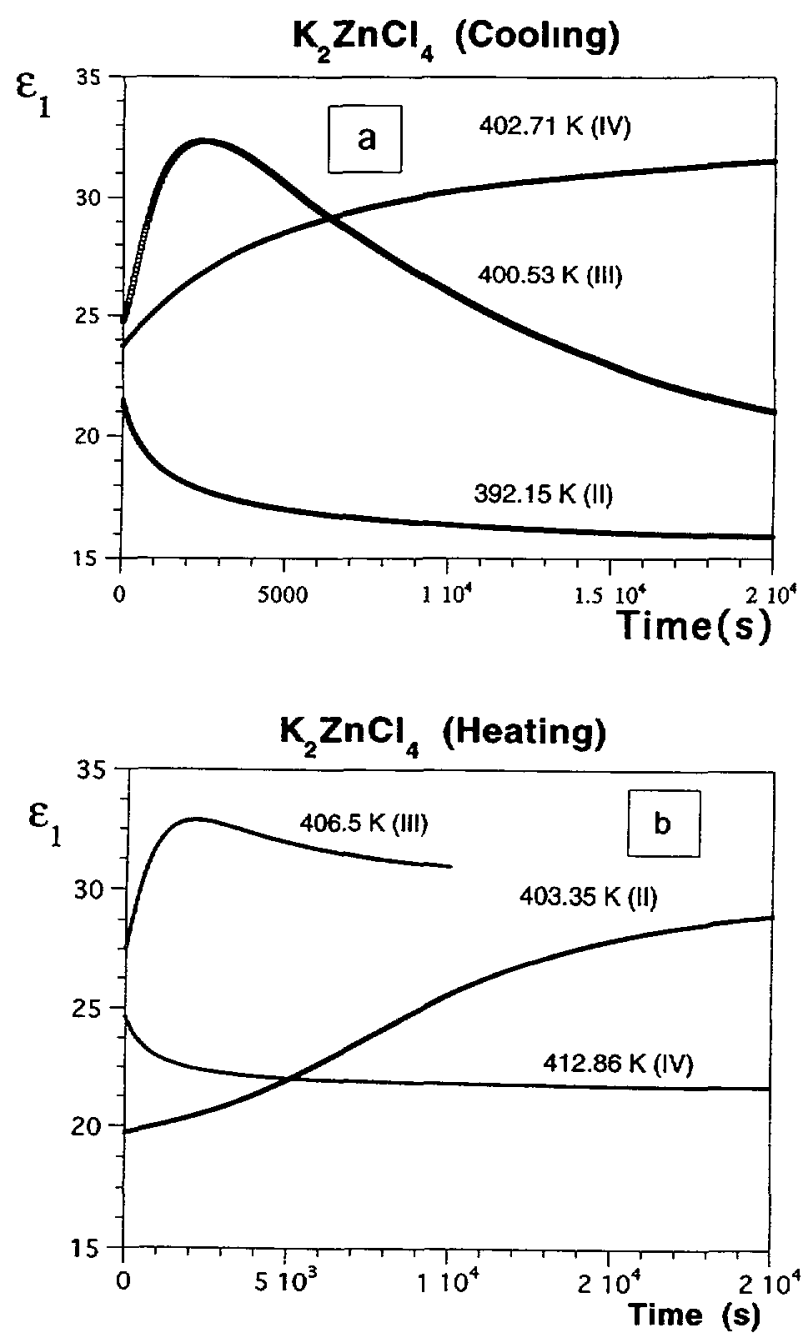

Fig. 2. - (a) Isothermal relaxations under coolıng conditions. The labels on each curve correspond to the temperature regions of figure 1a. (b) Isothermal relaxations under heatıng conditions. The labels on each curve correspond to the temperature regions of figure $\mathbf{l b}$. Note that the starting time of the experıments was taken $10 \mathrm{~s}$ after the temperature stabilization of the sample.

behaviour of the isothermal relaxations to our experimental procedure : at the initial stage of the relaxation, the system was in a fully non-equilibrium incommensurate state under either coolıng or heatıng conditions (see regions III in Figs. $1 \mathrm{a}$ and $1 \mathrm{~b}$ ).

\section{Discussion.}

In the vicinity of $T_{c}$, the anomalous dielectric susceptibility $\varepsilon_{1}(T)$ is usually written as [7]

$$
\varepsilon_{1}(T)=n(T) \exp (6 L \sqrt{v})
$$

where $n(T)$ is the density of discommensurations, $L$ the average distance between the discommensurations and $v$ an interaction term. Startıng from the incommensurate phase and 


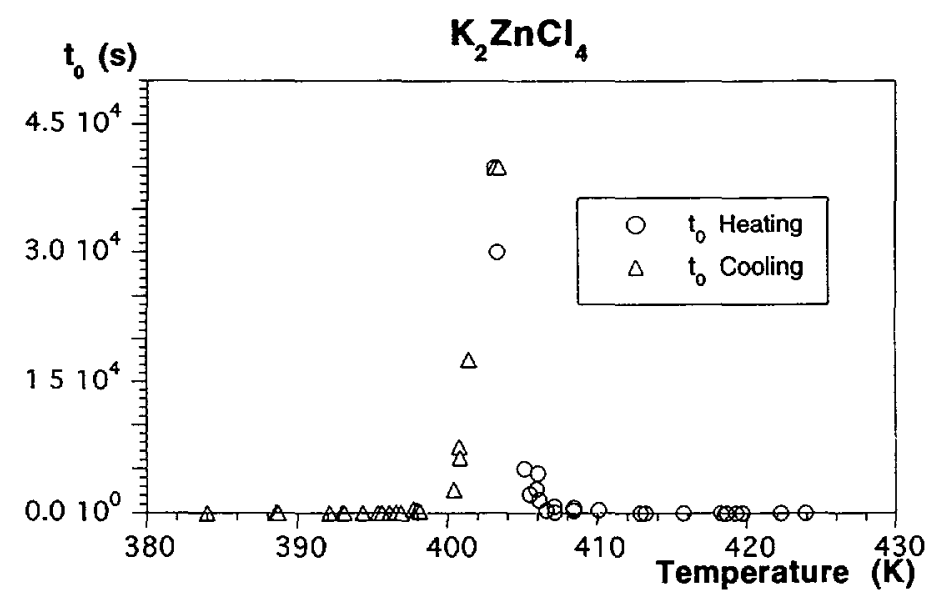

Fig. 3. - Crossover time $t_{0}$ versus temperature under cooling conditions (triangles) and under heatıng conditions (circles). The maxımum of $t_{0}$ is found to coincide for both sets of data.

cooling the sample, $n(T)$ decreases and $L$ increases. This leads to the divergence of $\varepsilon_{1}(T)$ at $T_{c}$. However, in real crystals, $n$ and $L$ are non-monotonous functions of the temperature : discommensurations may coexist with ferroelectric domain walls just below $T_{c}$. the structural defects and the surface of the sample have a pinning effect on the discommensurations. This has been discussed extensively in the literature for $\mathrm{K}_{2} \mathrm{ZnCl}_{4}[2,6]$ and $\mathrm{Rb}_{2} \mathrm{ZnCl}_{4}[8,9,10]$.

Our startıng point is that the isothermal relaxations that we have observed follow equation (2). It is the tıme evolution of $n$ and $L$ which governs the dielectric behaviour.

In a first step, we empirically compare our results with the $X$-ray data of Mashiyama and Kasatani [6]. In this work, it was shown that the isothermal dielectric relaxation close to $T_{c}$ was related to the relative evolution of the commensurate $I\left(\begin{array}{lll}2 & 0 & 2 / 3\end{array}\right)$ and incommensurate I $(202 / 3+\delta)$ peaks. Either on a coolıng or on a heating run, the dielectrıc maximum occurred under two conditıons [6]

(1) incommensurate and commensurate peaks were both detected,

(2) the commensurate intensity was almost negligible regarding the incommensurate one.

Even if these requirements remain qualitative, we can use them to infer the temperature evolution of $t_{0}$ the time where the dielectric maximum occurs. In fact, the relaxation time of the incommensurate line increases at $T_{c}$ [7]. This means that it takes a longer time for conditions (1) and (2) to be satisfied at $T_{L}$. It 1 s thus not surprising that $t_{0}$ increases at $T_{\iota}$ under etther coolıng or heating conditions.

We now turn to a description which was given by Hamano et al. [9]. These authors used a Landau-type model of a regular lattice of discommensurations to account for the isothermal relaxations in $\mathrm{A}_{2} \mathrm{BX}_{4}$ compounds. The free energy $F_{\mathrm{IC}}$ has two minima: one at 0 for the commensurate phase and one at $\delta$ which is the equllibrium misfit parameter at a given temperature. We note that in this model $\delta$ is proportional to the number of discommensurations. According to Hamano et al. [9], there is some equivalence between field induced and temperature induced isothermal relaxations. This is schematically depicted in figure 4 .

We first focus on the $\mathrm{C}$ to IC transition (Fig. 4). At the early stage of the isothermal relaxation, the system is suddenly brought from curve I to curve II During the whole isothermal relaxation on curve II, the number of discommensurations increases, thus 


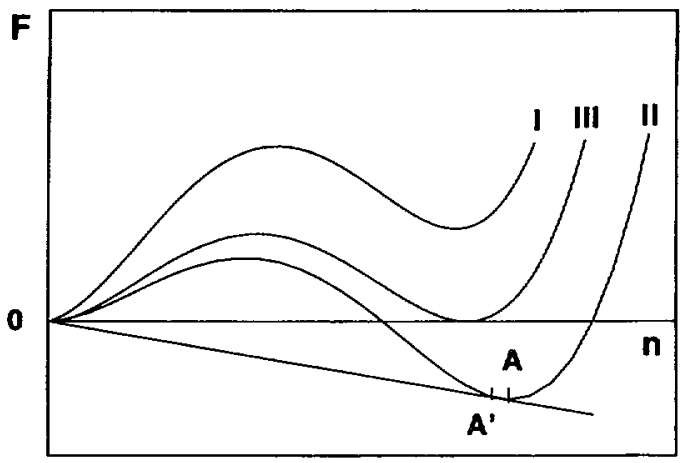

Fig. 4. - Theoretical variation of the free energy versus the number of discommensurations following Hamano [9]. Under heating conditions the isothermal relaxation proceeds from curve I to curve II. Under cooling conditions it goes from curve II to $\mathrm{I}$. $\mathrm{A}^{\prime}$ is the border point between a pure lattice of discommensurations and a mixed commensurate-mncommensurate phase. $A$ is the absolute minimum of the free energy in the incommensurate phase. Curve III is the critical free energy at $T_{c}$ where the relaxation is the longest.

increasing the dielectric susceptibility (see Eq. (2)). However, when the density of discommensurations is high, the average distance between them decreases and the exponential factor dominates the prefactor $n$ and the dielectric susceptibility decreases. This defines the observed crossover time $t_{0}$. In agreement with the experiments [6], Hamano et al. infer that this crossover occurs at a particular point $A^{\prime}$ on the free energy curve II. This point is on the border between a mixed $C$ and $I C$ phase (to the left of $A^{\prime}$ ) and a pure IC phase (to the right of $A^{\prime}$ ). Experimentally, this point is reached when the $C$ line disappears from the X-ray spectrum. Geometrically, $\mathrm{A}^{\prime}$ is the point where the tangent to the free energy curve meets the origin. Within this model, there is thus an agreement between our data and previous results from $[6,9]$. What is new is that we can explain why $t_{0}$ is the highest at $T_{\mathrm{c}}$. In fact, this temperature corresponds to the free energy curve III in figure 4 . On this particular curve, $A^{\prime}$ and $A$ are superposed and the crossover would take an infinite time to occur.

On a cooling run (IC to $C$ transition), we can reverse the above description and find that $t_{0}$ is the time when $A^{\prime}$ is crossed between steps 2 and 3 of the relaxation (Fig. 4, curve I). During step 2, it is the exponential factor of equation (2) which allows for the increase of the dielectric susceptibility while the number of discommensurations is decreasing. Again, the maximum crossover time is found when the free energy curve has two degenerate minıma at $T_{\mathrm{c}}$.

We thus propose that the crossover tıme $t_{0}$ be a relevant parameter for the incommensurateferroelectric phase transition in $\mathrm{K}_{2} \mathrm{ZnCl}_{4}$. The temperature variation of $t_{0}$ is reported in figure 3 . Within the overall experımental error $(\Delta T=0.1 \mathrm{~K})$, the two heatıng and coolıng curves for $t_{0}$ merge at $403.5 \mathrm{~K}$. For temperatures higher than this characteristic temperature under heating conditions, $t_{0}$ escapes our time scale $(24 \mathrm{~h}$ maxımum). The same effect occurs on cooling conditions at temperatures lower than $403.5 \mathrm{~K}$. To our knowledge, it is the first time that a physical quantity displays this kind of behaviour in $\mathrm{K}_{2} \mathrm{ZnCl}_{4}$. In fact, the other parameters which we calculated from the isothermal data, $\tau$ and $\varepsilon_{\infty}$ have a hysteresis of more than $5 \mathrm{~K}$.

The common temperature where $t_{0}$ has the same value both under cooling or heating conditions could be a very specific feature of $\mathrm{K}_{2} \mathrm{ZnCl}_{4}$. Is this the «true » transition temperature? Even if it lies within the thermal hysteresis of the dielectric susceptibility [2], some care is required. In fact, from $\mathrm{DC}$ field experıments in $\mathrm{Rb}_{2} \mathrm{ZnCl}_{4}$, it was shown that 
$t_{0}$ is very sensitive to the defect content of the sample $[8,10]$. It was possible to decrease $t_{0}$ by two orders of magnitude in purified $\mathrm{Rb}_{2} \mathrm{ZnCl}_{4}$ as compared to standard samples. This was a proof for a pinning of discommensurations by lattice defects, the lower the defect density, the shorter the crossover time $t_{0}$. This pinning effect has obviously to be taken into account in $\mathrm{K}_{2} \mathrm{ZnCl}_{4}$. The high value of $t_{0}$ that we have observed is the signature of a rather high density of defects. This is consistent with the minimum hysteresis of $5 \mathrm{~K}$ in our samples.

However, the pinning has no measurable effect on the temperature variation of $t_{0}$. This variation probes the intrinsic dynamics of the discommensurations while the absolute value of $t_{0}$ is sensitive to the interaction of the discommensurations with the defects. To confirm this point, it would be interesting to apply our experimental procedure to high purity $\mathrm{K}_{2} \mathrm{ZnCl}_{4}$ and $\mathrm{Rb}_{2} \mathrm{ZnCl}_{4}$.

To summarize, we have observed a non-monotonous isothermal relaxation of the dielectric susceptibility of $\mathrm{K}_{2} \mathrm{ZnCl}_{4}$. This is consistent with the radio frequency dielectric data reported previously [5]. Our data are also consistent with the model proposed by Hamano et al. for $\mathrm{Rb}_{2} \mathrm{ZnCl}_{4}$ [8]. Moreover, we have been able to measure such anomalous relaxations starting etther from the incommensurate or from the ferroelectric phases. This was possible because we did not use a DC electric field but a high thermal variation rate as the driving source for a nonequilibrium initial state. We thus confirmed that the competition between ferroelectric domain walls and incommensurate discommensurations leads to an extremum in the susceptibility relaxation. We have shown that the crossover time between both dynamics tends to diverge near $T_{c}$.

\section{References}

[1] Gesı K., J. Phys. Soc. Jpn 45 (1978) 1431.

[2] Xiaoqing P. and Unruh H. G., J. Phys. Cond. Matter 4 (1992) 6899.

[3] Unruh H. G. and Levtsık A., Ferroelectrics 78 (1988) 259.

[4] Levtsik A., Prelovsek P., Filipıc C. and Zeks B., Phys. Rev. B 25 (1982) 3416.

[5] Ema K., Izumı H. and Hamano K., Jpn J. Appl. Phys. Suppl 24-2 (1985) 799.

[6] Mashiyama H. and Kasatanı H., Jpn J. Appl. Phys. Suppl. 24-2 (1985) 802.

[7] Mashiyama H. and Kasatanı H., J. Phys. Soc. Jpn 56 (1987) 3347.

[8] Hamano K., Sakata H., Izumı H., Yoneda K. and Ema K., Jpn J. Appl. Phys. Suppl. 24-2 (1985) 796.

[9] Hamano K., Sakata H. and Ema K., Ferroelectrics 137 (1992) 235.

[10] Cummins H. Z., Phys. Rep. 185 (1990) 211.

[11] Gridnev S. A., Prasolov B. N. and Gorbatenko V. V., Ferroelectnics 126 (1992) 1069. 